\title{
O CRISTIANISMO E SUAS FORMAS DE VERIDICÇÃO: RESSONÂNCIAS FOUCAULTIANAS
}

\author{
[CHRISTIANITY AND FORMS OF VERIDICTION: FOULCAULTIAN RESONANCES]
}

Resumo: A introdução do cristianismo enquanto objeto de análise na obra de Michel Foucault marca um novo momento em sua trajetória intelectual, onde $\mathrm{o}$ autor se compromete ao projeto de uma genealogia da ética e dos processos de subjetivação no ocidente. O objetivo deste artigo consiste em apontar a importância do cristianismo nas formulações que Foucault fez a partir da segunda metade da década de 1970, especialmente no que se refere aos seus estudos sobre ética, subjetividade e verdade. Para isso, foi analisada o desenvolvimento do tema nas obras do intelectual, em especial os cursos ministrados no College de France. Outro ponto central a discussão foram os conceitos de exolomogese e exagoreusis, formas de penitência presentes no cristianismo que apontam para um deslocamento do funcionamento dos regimes de verdade no ocidente. $\mathrm{O}$ deslocamento do pagamento da penitência como um ato público performático para o de uma confissão pela palavra pode ser rastreado como um ponto de ligação entre as práticas cristãs e a subjetividade moderna, no que diz respeito a produção de formas de interpretação e relação consigo mesmo a partir
ABSTRACT: The introduction of christianity as an object of analysis in the work of Michel Foucault marks a new moment in his intelectual course, Where the author commits hinself to the project of a geneology of ethic and forms of subjectivation in the West. The objetive of this paper consists in pointing to the importance os christianity in the formulations that Foucault made startings in the 1970's, specially on what concerns to his studies on ethic, truth and subjectivity. For that, we analyzed the development of this the me in the intelectual's work, specially the courses ministraded by Foucault in College de France. Another central point to the discussion were the concepts os exomologesis and exagoreusis, forms of penitence in christianity which points to a shift in how regimes of truth function in the West. The shift in paying penitence as a public performative act to a confession by word can be traced as a point of conection between christian practices and modern subjectivity, in that of which concers to the Productions of forms of interpretation and relation of the subject with itself based on confessional dispositives. Finally we searched, based on foucaultian thought, to make a paralel between the christian

* Doutorado em Filosofia pela Fundação Universidade Regional de Blumenau. Colaborador do Mestrado em Educação da Fundação Universidade Regional de Blumenau, FURB. E-mail: diazsoler@gmail.com.** Doutorado em História pela Universidade Federal de Santa Catarina, UFSC. Professor do Departamento de História do Centro Universitário Facvest, UNIFACVEST. E-mail: araldivaz@yahoo.com.br.***Fundação Universidade Regional de Blumenau, FURB. Email: alois.miguel@gmail.com 
de dispositivos confessionais. Por fim, penitential dispositive of exagoreusis and buscamos, a partir do pensamento foucaultiano, different power-knowledge relations of realizar um paralelo entre o dispositivo modernity (such as law, psychiatry and penitencial cristão da exagoreusis e diferentes psychology) that utilize the confessional dispositivos de saber-poder da modernidade alegory as a disciplinary practice and (como o direito, a psiquiatria e a psicologia), Productions of subjectivity and truth.

que utilizam da alegoria confessional enquanto KEYWORDs: Michel Foucault, chrisitianity, prática disciplinar e de produção de forms of veridication

subjetividade e verdade.

Palavras-ChaVe: Michel Foucault; cristianismo; formas de veridicção

\section{INTRODUÇÃo}

T $\mathrm{m}$ dos maiores projetos presentes na trajetória intelectual de Michel Foucault, de acordo com Candiotto (2008), consiste em uma problematização acerca das produções históricas em torno dos regimes de verdade. Em linhas gerais, o próprio Foucault reitera essa posição, ao anunciar que:

A hipótese que gostaria de propor é que, no fundo, há duas histórias da verdade. A primeira é uma espécie de história interna da verdade, a história de uma verdade que se corrige a partir de seus próprios princípios de regulação: é a história da verdade tal como se faz na ou a partir da história das ciências. Por outro lado, parece-me que existem, na sociedade, ou pelo menos, em nossas sociedades, vários outros lugares onde a verdade se forma, onde um certo número de regras de jogo são definidas - regras de jogo a partir das quais vemos nascer certas formas de subjetividade, certos domínios de objeto, certos tipos de saber - e por conseguinte podemos, a partir daí fazer uma história externa, exterior da verdade. (FOUCAULT, 2011, p. 20-21).

Conforme essas palavras apontam, o segundo eixo dessa "história exterior da verdade" a qual fala Foucault apresenta-se como uma categoria imprescindível para uma possível leitura em torno dos modos pelos quais o sujeitos, são levados a modular os seus processos de subjetivação a partir de diferentes tensionamentos entre as estratégias de saber e as práticas de poder. Ora, o que procuramos afirmar, segundo Foucault (2009), é que o sujeito é um efeito da política agônica dos jogos de verdade a partir das relações entre diferentes regimes de discursividades, de dispositivos de poder e de experiências éticas.

É nesse sentido que se direciona grande parte das reflexões desenvolvidas por Foucault, sobretudo, a partir da segunda metade da década de 70, quando ele procura estabelecer uma genealogia das práticas de governo na sociedade ocidental. Dentro de tal problemática, o cristianismo ocupa um papel central nas prática de veridicção e produção de modos de subjetivação. Na conferência intitulada Sexualidade e Poder, Foucault entende que o papel do cristianismo nas sociedades ocidentais vai muito além da estruturação de um sistema ideológico de repressão moral sobre as condutas, uma vez que: 
[...] é mais do lado dos mecanismos de poder do que do lado das ideias morais e das proibições éticas que é preciso fazer a história da sexualidade no mundo ocidental desde o cristianismo. A questão é então: quais são os novos mecanismos de poder que o cristianismo introduziu no mundo romano, valorizando essas proibições que já eram reconhecidas e aceitas? Esse poder é o que chamarei - ou melhor, é o que se chama - de pastorado, ou seja, a existência dentro da sociedade de uma categoria de indivíduos totalmente específicos e singulares, que não se definiam inteiramente por seu status, sua profissão nem por sua qualificação individual, intelectual ou moral, mas indivíduos que desempenhavam, na sociedade cristã, o papel de condutores, de pastores, em relação aos outros indivíduos que são como ovelhas ou o seu rebanho (FOUCAULT, 2014a, p. 6334).

Dito de outro modo, o papel do cristianismo na nossa sociedade teria sido o de elaborar uma complexa rede de dispositivos responsável pela produção de uma prática refletida de governo voltada para a direção das condutas. Direção esta que, por sua vez, é delimitada por distintos procedimentos de veridicção orientados por uma paradigma ético, estético e político nas relações entre verdade e subjetividade.

Ou seja, segundo Foucault (2008), o grande mérito do cristianismo foi o de ter introduzido, em nossa cultura, uma prática de poder específica segundo a qual, o sujeito somente pode reconhecer-se como si mesmo a partir da vigilância intensa das suas próprias atitudes perante uma determinada forma de governamentalidade. Isto é, o cristianismo modula um processo de subjetivação responsável por ligar as experiências éticas a regimes de verdades instituídos pela obediência irrestrita e pela confissão. Isso porque, segundo Foucault (2010, p. 360):

No cristianismo, o laço com o pastor é um laço individual, um laço de submissão pessoal. Sua vontade é realizada não porque ela é conforme a lei, mas principalmente, porque tal é sua vontade. Nas Instituições Cenobíticas de Cassiano, encontramos várias historietas edificantes nas quais o monge encontra sua salvação executando as ordens mais absurdas de seu superior. A obediência é uma virtude. O que quer dizer que ela não é, como para os gregos, um meio provisório para alcançar um fim, mas antes um fim em si. É um estado permanente; as ovelhas devem permanentemente submeter-se a seus pastores: subditti.

Não se trata somente de obedecer, mas também reconhecer-se enquanto sujeito da dívida e da culpa por meio de diferentes rituais de mortificação e culpabilização. Esse exercício do governo da verdade pelas mãos do cristianismo converge portanto, na produção de sujeitos e formas de subjetividade governáveis.

A finalidade desse artigo consiste em rastrear, a partir das contribuições desenvolvidas por Foucault, esses elementos de veridicção tomando o cristianismo com efeito de subjetividade. Nesse contexto, apresentar-se-á em um primeiro momento as dimensões efetivas das práticas de veridicção a partir de um diálogo, promovido por Foucault em torno da exomologese e da exagoreusis, duas práticas de penitências desenvolvidas pelo cristianismo, para em um segundo momento, se apontar os desdobramentos dos dispositivos confessionais enquanto regimes de verdades. Nossas considerações finais são dedicadas a explorar as ressonâncias dos modos de veridicção do cristianismo a partir da formação do que chamamos de governo das subjetividades.

\section{O QUE É UMA VERIDICÇÃO PENITENCIAL?}

É no curso ministrado no Collège de France entre 1979 e 1980, intitulado Do 
Governo dos Vivos, que Foucault (2016) aponta as condições de possibilidades para o exercício do cristianismo como uma prática de veridicção. Em linhas gerais, o referido curso trata de articular, por meio de uma reflexão histórica, o desenvolvimento das práticas penitenciais entre os séculos IV e V com a formação de uma vontade de saber ${ }^{1}$, presente na formação dos dispositivos confessionais. Desdobrado nesse objetivo, podese encontrar a realização, por parte de Foucault (2016), de uma leitura em torno dos modos pelos quais a exomologese cristã - ritual de penitência marcado pela exposição pública e performática do pecador, para lhe conferir o status de penitente - emerge como categoria originária das práticas de penitências e, aos poucos, vai migrando para $\mathrm{o}$ campo da exagoreusis ou, como aponta Colombo (2015), para a formação de uma hermenêutica de si. Ou seja, Foucault (2016) trata de investigar trata de investigar a passagem de uma ritualística representativa da vida monástica em direção a emergência de uma forma de vida permeada pela reação entre verdade, subjetividade e interioridade.

Para Foucault (2016), esse conjunto de técnicas não se configura como um mero ato da liturgia cristã, mas opera como uma complexa engrenagem pela qual são articuladas as experiências éticas e os modos de veridicção. Entretanto, antes que se prossiga é necessário questionar-se: quais os principais pontos de marcam a relação entre a exomologese e a exagoreusis em torno do problema da verdade e da subjetivação? e ainda, quais as rupturas que favoreceram a passagem da penitência enquanto um gesto público, para o domínio da vida privada?

A partir do estudo das formas de vida do monacato Foucault (2016), acaba por encontrar, nos interstícios do sacrifício penitencial, o emblema da exomologese. Caracterizada como um gesto público, pelo qual, o pecador deveria manifestar a sua verdade ascendendo ao estatuto de penitente. Esse estatuto, por sua vez, era outorgado pela autoridade eclesiástica, pois segundo Foucault (2016, p. 178):

A penitência canônica é considerada como a segunda penitência, isto é, como o
que, do batismo, repete o acompanhamento penitencial, a disciplina penitencial
que lhe era ligada. É dessa segunda penitência que gostaria de falar, porque está
ligada à segunda penitência toda uma série de procedimentos de verdade que
assinalam, me parece, uma inflexão considerável no que poderíamos chamar de
relações de subjetividade com a verdade, não apenas no cristianismo, mas em
toda a civilização ocidental.

$\mathrm{Na}$ opinião de Chevalier (2012), essa compreensão analítica promovida por Foucault em relação a exomologese como uma prática de veridicção, configura-se como uma prática refletida de governo em que o sujeito estetizava-se pela dramaturgia pública de um ato confessional, manifestando dessa maneira, a sua própria verdade. Tal prerrogativa era configurada pelo que Foucault (2016) chama de spositio casus, isto é, um procedimento responsável por implicar o penitente no exercício de veridicção pela declaração, perante o bispo dos pecados cometidos.

Ao estabelecer essa forma de vínculo, a exomologese acaba por se configurar como uma forma de expressão performática da verdade. Ou seja, estamos diante de uma aleturgia do ato penitenciário, pelo qual o sujeito deveria, antes de reconciliar-se com Deus, assumir publicamente a sua condição de penitente. Entretanto, o próprio Foucault (2016) adverte-nos que essa spositio casus decorrente da exomologese não deve ter sua compreensão limitada a um mero ato punitivo e/ou disciplinar, mas sim enquanto um regime próprio de governo sobre a vida devota. Nesse sentido, a exomologese enquanto prática de veridicção constitui-se como um emblema de um habitus, uma forma de vida. Para Agamben (2014, p. 101), a existência desse habitus configura-se como uma vontade jurídica da estilística da existência própria ao regime de governo cristão cuja 
experiência será decisiva para os contornos das formas de subjetividades modernas, pois ele nos lembra que:

O sentido de forma é, nesse caso, "exemplo paradigma"; mas a lógica do exemplo não é de modo algum simples, e não coincide com a aplicação de uma lei universal. Forma vitae designa, nesse sentido, um modo de vida que, ao aderir estreitamente a uma forma ou modelo, de que não pode ser separado, se constitui por isso mesmo como exemplo.

Tal perspectiva nos ajuda a compreender como a spositio casus efetiva-se por meio de uma forma de vida acoplada a um ordenamento jurídico da existência por meio dos procedimentos voltados para atos públicos que deveriam manifestar a verdade do sujeito como regra fundamental do que Foucault (2016) chama de tentação ontológica do cristianismo, isto é, a premissa de que uma existência somente torna-se possível por conta da alegoria das práticas de veridicção intrínsecas ao sacrifício penitencial. Tratase de uma manifestação corporal da verdade. Já que o sinal empregado por Foucault (2016) acerca do mundo cristão vai além do estudo das normas, das leis ou mesmo do direito canônico, são procedimentos como os empregados pela exomologese que interessam no sentido de situarem-se as ações dos sujeitos em torno dos elementos de veridicção.

Em outras palavras, o que procura-se afirmar é que a exomologese constitui-se como elemento fundamental para a potencialização das formas de verdades do cristianismo a partir do conjunto de suas práticas. Por sua vez, o que está em jogo nesse conjunto de práticas penitenciais são os gestos praticados pelo sujeito tomando como efeito a sua própria conversão.

No que corresponde a esse estilo de confissão pública em que a exomologese se apresenta, conforme Candiotto (2012) como um estilo específico praticado e difundido pelo monacato, sobretudo a partir da emergência no século IV com a emergência do cenobitismo. É a partir desse momento histórico que a produção de verdade ganha um estatuto de visibilidade voltado para à direção de consciência tomada como ritual de mortificação do próprio corpo do sujeito. Esse efeito acaba por sinalizar, de acordo com Foucault (2016) os traços de uma correlação muito importante entre verdade e subjetividade a partir da proliferação das práticas penitenciais em comunidades religiosas.

Efeito de lapidar, portanto, um regime específico de direção de consciência na qual o sujeito deveria colocar o próprio corpo à prova das tentações que cometera, como também as tentações que afligiam o seu próprio desejo. Exercer a exomologese significava portanto, prostrar-se perante à autoridade eclesiástica, perante toda a comunidade, mas acima de tudo, denotava prostrar-se em relação a si mesmo.

Contudo, um acontecimento político acarretará na decadência desse estilo de veridicção, a qual a exomologese estava vinculada. Tal acontecimento refere-se, na opinião de Foucault (2016), a instauração nos intramuros dos monastérios de uma nova regra da obediência cristã, segundo a qual o sujeito deveria passar a verbalizar exaustivamente os seus mais íntimos desejos. Entretanto, a pergunta que poderia ser feita é: em que consiste essa nova modalidade de prática confessional presente na obediência completa?

Em primeiro lugar segundo Foucault (2016), esse novo estilo confessional é constituído por uma ritualística na qual o sujeito deveria converter o olhar para si mesmo. Ou seja, tratava-se de fazer de si mesmo um objeto de análise. Essa prática ficou conhecida como exagoreusis, o instante preciso em que o sujeito deveria proceder uma hermenêutica de si mesmo como armadura da sua própria verdade. A outra explosiva e pirotécnica exomologese, aos poucos, cede espaço para a intimização dos 
primeiros rituais confessionais sobre a carne, passagem essa que podemos apontar também como se deslocando do ato para a palavra. A desconfiança sobre si mesmo ganha um novo contorno a partir da exagoreusis. Agora, o problema não reside mais na humilhação e exposição pública da condição do sujeito, mas sim no reconhecimento, por parte de si mesmo, de uma interioridade que deveria sempre ser relatada ao outro. A suspeita de si, ou o combate a interioridade é assim descrita por Foucault (2019, p.135):

O problema que ela pode introduzir leva dois aspectos principais. Os da multiplicidade, da mobilidade, da desordem, onde a alma precisa de ordem, estabilidade e da sua unidade sem movimento. E o de se efetivar como a contemplação única do ser supondo que o pensamento seja mantido para esse único fím e nunca se desvie dele. Tarefa extremamente difícil $<<$ Quem será capaz de criar, de todos os santos justos e mais eminentes, que eles conseguiram, nos laços desses corpos mortais, possuir invariavelmente o bem soberano? nunca deve-se desviar da contemplação divina, nem se distrair um instante, com pensamentos terrenos $>>$. $^{2}$

É a partir desse combate a toda e qualquer forma de pensamento que desvie o sujeito da sua meta transcendental, que os padres cristãos irão desenvolver o conceito de discretio, com a finalidade de evitar o relaxamento e a vaidade como os grandes obstáculos para a hermenêutica do sujeito. Diferentemente da temperança grega, a discretio cristã entendia o que o sujeito era incapaz de exercer o autogoverno, faltandolhe uma mediação permanente entre a obediência e a autoridade.

Esse processo de subjetivação presente no monacato era composto por um duplo aspecto: o primeiro referente a uma desordem conjetural e o segundo por um problema de ordem teológica. Em relação a desordem conjetural, a questão recaia sobre a desconfiança da instituição monástica em relação ao que Foucault (2016) chama de excesso de ascetismo. Ou seja, ao mesmo tempo que o sujeito era convocado a produzir uma ruptura em relação à materialidade do mundo, ele deveria lembrar-se de que era necessário efetivar o mais absoluto respeito em relação às instituições monásticas e às comunidades eclesiásticas. Quanto ao problema de ordem teológica, ela referia-se a constatação de que a presença de Satanás e no corpo do sujeito era resultado de três elementos distintos. A perenidade, ou seja, o fato de que ela é permanente, desde a concepção do sujeito. A subjetividade, já que Satanás tentava constantemente possuir a alma do sujeito. Por fim, a corporalidade, já que essa instância era considerada o templo impuro no qual residia a figura do próprio Diabo conduzindo o sujeito sempre ao erro.

A esse respeito, nos lembra Colombo (2015), que a condição de possibilidade a emergência da exagoreusis seria, justamente, a presença da discretio como condição ontológica do exame de si. A verbalização desse novo estatuto de veridicção foi responsável, por operar conforme aponta Foucault (2016) uma espécie de disseminação do sentimento de vergonha e de culpabilização permanentes nas atitudes do sujeito. Por sua vez, a discretio acaba adotando todo um estilo, cuja natureza é reiterada pelo paradigma cosmo-teológico, em que os pensamentos satânicos só podem sucumbir mediante a obediência irrestrita. Um outro ponto importante a esse respeito, refere-se ao fato de que essa nova configuração dos atos de verdade, eram orquestrados por meio da organização de combate permanente entre o pecador e os seus próprios pensamentos que, somente se atenuarão, por meio da confissão incondicional a partir da sua verbalização. A palavra torna-se um elemento preponderante para os procedimentos de veridicção ligados ao regime de governamentalidade cristã.

Ora, o que está em jogo é a própria conversão do sentido originário da confissão, ou seja, a passagem da exomologese - compreendida como gesto explosivo de aspiração do sujeito em relação a uma vida penitente - para a exagoreusis. Essa 
exagoreusis apresenta-se, portanto como um dispositivo confessional muito mais complexo e refinado no sentido de estabelecer os parâmetros pelos quais o sujeito deveria externalizar, pela palavra, desde os seus pensamentos mais ínfimos, mesmo a gestação de ideias deveria ser compartilhada com a finalidade de se proceder a hermenêutica de si.

Desse modo, o problema para Foucault (2016) consiste em estabelecer a partir desse tensionamento entre exomologese e exagoreusis, os motivos pelos quais a primeira deixa de ser aplicada enquanto prática de veridicção desaparecendo quase que completamente do estatuto do governo monástico, em nome da proliferação de um giro hermenêutico que liga à confissão e aos modos de veridicção por meio da mediação da palavra. Essa perspectiva permite com que se estabeleça um ponto fundamental entre os modos de veridicção e o cristianismo a partir de um problema muito importante destacado por Foucault (2013/2018) em cursos como A Hermenêutica do Sujeito e Subjetividade e Verdade no que se refere ao problema do conhecimento de si e dos processos de subjetivação. Nesse novo estilo ritualístico entre sujeito e verdade, passa a se configurar como um problema cada vez mais urgente para as políticas de governamentalização da vida, uma espécie de autossuficiência responsável por estabelecer a correlação entre a hermenêutica de si e o sujeito do cogito e/ou impensado. A exagoreusis passa a definir as regras e as condições de possibilidades para a emergência do que Foucault (2013) chama de momento cartesiano das práticas de veridicção, pois segundo ele mesmo aponta, "A verdade só é dada ao sujeito a um preço que põe em jogo o ser mesmo do sujeito (FOUCAULT, 2013, p16)."

Percebe-se que o aporte responsável por ligar o projeto da confissão monástica a racionalidade moderna da subjetividade, não é retilínea, mas cheia de desníveis, rupturas e descontinuidades. Nesse caso, a conexão entre a confissão cristã e a subjetividade moderna efetiva-se pela consideração dos diferentes percursos metodológicos da interpretação da verdade e das relações do sujeito consigo mesmo a partir de jogos de forças e relações discursivas que tomam o sujeito como objeto não somente de uma perspectiva transcendental, mas também pelo embate agônico das faltas e da própria invenção da ideia de interioridade subjacente e, ao mesmo tempo desconhecida.

\section{FAZER O MAL E DIZER A VERDADE: DISPOSITIVO CONFESSIONAL E A HERMENÊUTICA DE SI}

Em 02 de abril de 1981 Foucault promove uma série de conferências na Universidade de Louvain. Logo na primeira conferência ele promove um resgate de um acontecimento singular envolvendo um dos pais da psiquiatria moderna, no caso, o médico francês François Leuret:

Em uma obra consagrada ao tratamento moral da loucura e publicada em 1840, Leuret, um psiquiatra francês, se refere a maneira como havia tratado a um de seus doentes. O senhor A. possuía um delírio persecutório e alucinações. Uma manhã Leuret o leva ao chuveiro e o coloca em pé sob a ducha. Tem início então uma longa conversa, que resumo. O médico pede ao paciente que conte detalhadamente o seu delírio. $O$ doutor Leuret: em tudo isso não há uma só palavra que seja verdadeira; você fala loucuras. E por estar louco, o trouxemos para Bicêtre. $O$ paciente: Não creio que estou louco. Sei o que vi e ouvi. $O$ doutor Leuret: Se queres que esteja de acordo com você, tens que obedecer, porque tudo que lhe peço é razoável. Você me promete não pensar mais em suas loucuras, me promete não falar mais delas? Vacilante o enfermo promete. O doutor Leuret: 
Você faltou muitas vezes com sua palavra em relação a esse ponto: não quero contar com suas promessas; você vai receber uma ducha até que confesse que todas as coisas que disse não são mais que loucuras. Na sequência lhe aplicam uma ducha gelada sobre a cabeça. $\mathrm{O}$ enfermo reconhece que suas imaginações não eram mais que loucuras e que irá tratá-la. Mas adverte: eu reconheço isso porque me obrigam a fazê-lo. Nova ducha gelada. Sim senhor, tudo o que the disse são loucuras. Você estava louco então, pergunta o médico? O enfermo vacila: creio que não. Terceira ducha gelada. Estavas louco? O paciente: ver e ouvir é estar louco? Sim. Então, o paciente termina por dizer: Não haviam mulheres que me insultavam, nem homens que me perseguiam. Tudo isso era uma loucura (FOUCAULT, 2014b, 21-22). ${ }^{3}$

Essa conversação apresenta um ponto muito importante sobre o tratamento da doença mental no século XIX: uma alegoria confessional, em que, ao paciente não lhe é dada outra alternativa senão reconhecer a própria loucura como um objeto de conscientização. Esse procedimento de imersão do pobre infeliz ao banho gelado possui a finalidade de despertá-lo para o mundo da racionalidade admitindo a sua própria culpa. Entretanto, não é somente a punição que lhe desperta para a convicção de que seus delírios não fazem parte da realidade, mas sim a palavra chave para todo esse "sucesso terapêutico": a confissão. Antes de mais nada, era preciso que o sujeito admitisse e reconhecesse a própria loucura admitindo por sua vez, as suas próprias falhas. De acordo com Jérôme (2018), não se trata para Foucault, de compreender tal atitude realizada por Leuret como um mero processo disciplinar, mas sim evidenciar o gesto explosivo pelo qual o psiquiatra em questão atualiza o elemento confessional como um dispositivo entre a racionalidade e o dizer verdadeiro.

Embora exista uma enorme diferença epistemológica e ideológica entre o regime de governamentalidade cristão e a psiquiatria moderna, isso não inviabiliza o fato de que ambas estão articuladas a uma experiência responsável por compreender a confissão como uma alegoria intrínseca a verdade sobre si mesmo. Essa experiência é o que poder-se-ia chamar de exigência da confissão e, nesse caso, o problema fundamental reside em correlacionar os efeitos do dispositivo da confissão como obrigação do sujeito em manifestar a verdade. Isto é, trata-se para Foucault (2014b) de rastrear, por meio do método genealógico, quais seriam as formas pelas quais se articulam as questões históricas, filosóficas e políticas responsáveis por fazer da confissão um elemento fundamental dentro dos modos de subjetivação, tomando a confissão não somente como um ato enunciativo, mas sim um dispositivo circunscrito nas entrelinhas da dramaturgia do ato confessional.

Segundo apontam Muchail e Fonseca (2019), essa dramaturgia da qual fala Foucault, percorre os sentidos e significados de uma prática aletúrgica responsável pela formação de um vínculo entre aquilo que se afirma e aquilo que se é. Portocarrero (2019), possui opinião semelhante ao entender que não pode existir a confissão sem que exista o engajamento e o desejo de confessar. Essa ideia é portanto, fundamental para que se compreenda como a verdade passa a ser trabalhada no panorama das relações entre o cristianismo e as formas modernas de subjetividade por meio da implicação do sujeito em relação a obrigação do sujeito permanentemente afirmar quem é, nas suas mais distintas práticas sociais. O que procura-se afirmar é que o cristianismo abre espaço para a constituição de um elemento substancial ao problema da modernidade, no caso, as experiências dos modos de veridicção. A confissão torna-se, nesse caso, um problema relacionado as experiências éticas pelas quais o sujeito liga a verdade sobre si mesmo às estratégias de saber, às práticas de poder e aos processos de subjetivação.

Nesse sentido, pensar a genealogia das práticas confessionais consiste em 
reconhecer sua importância para o conjunto de várias experiências em que a veridicção torna-se o emblema recorrente para o exercício da subjetividade. Ou seja, mais do que investigar os percursos de secularização dos dispositivos confessionais aplicados a governamentalização da vida, Foucault (2014b) insiste em nos mostrar que é por meio da confissão - praticada inicialmente nos monastérios católicos - que se produzem formas de subjetividades que são capturadas pelos regimes de governamentalização da vida. É por meio de tal perspectiva que Foucault (2014b) incita-nos a uma reflexão crítica sobre as formas de subjetividades na nossa sociedade como um todo. Se compreendermos essa crítica como um movimento de problematização da nossa atualidade, há de se perceber que, uma das tarefas políticas mais importantes para a nossa atualidade, é recusarmos e resistirmos às diferentes formas de subjetividades, capturadas pelos dispositivos de poder, pois conforme apontam Dreyfus e Rabinow (1995, p. 220) "A interpretação e o sujeito moderno implicam-se mutualmente. As ciências interpretativas partem da ideia de que há uma verdade profunda conhecida e escondida".

Trata-se portanto, de nos perguntarmos sobre os jogos de verdades presentes nas práticas de captura, pois acima de tudo, a veridicção está ligada às formas de vínculos produzidas pelos sujeitos. O problema reside em investigarmos quais seriam as condições de possibilidades para a emergência de estratégias de resistências contrárias às técnicas de governo responsáveis por produzir processos de subjetivação inscritos nos rituais de mortificação, cuja proveniência remete ao cristianismo.

Nesse sentido, o estudo sobre as formas de confissão acabam por sinalizar o que Foucault (2014b) chama de etnologia política do dizer verdadeiro. Essa perspectiva não limita-se ao empreendimento sobre as condições formais ou empíricas do discurso verdadeiro, mas sim afirmar que os modos de veridicção operam como uma prática social, isto é, o conjunto de forças responsáveis por vincular o sujeito a determinados modos de governamentalização.

\section{CONSIDERAÇÕES FINAIS}

Ao proceder à análise das práticas de veridicção Foucault (2016) acaba por nos sinalizar que, na construção de um projeto como o de uma história política e ética da verdade e dos processos de subjetivação, nossa proveniência seria, sem sombra de dúvida, as culturas grega e romana, pois é a partir delas que foram pensadas as articulações entre o governo de si e dos outros. Entretanto, do ponto de vista estrutural, o cristianismo acaba por se destacar neste projeto por incorporar esses elementos de governo da vida, convertendo-os em novas formas de subjetivação voltadas para a ascensão da vida penitencial, da desconfiança de si mesmo e da hermenêutica de si.

Desse modo, o cristianismo ocupa um papel importantíssimo no que se refere ao processo de governamentalização a partir dos exames confessionais, acabando por fazer do cristianismo um amplo campo analítico dentro do pensamento foucaultiano.

É nesse contexto do cristianismo como prática de veridicção que Foucault (2016) estabeleceu sua problematização genealógica da formação, na nossa sociedade, do que ele chama de aveu (FOUCAULT, 2019), ou seja, uma prática pela qual a subjetivação é produzida a partir de uma estrita correlação entre a exomologese, a exagoreusis e os dispositivos de veridiçcão da modernidade presentes em saberes como o Direito, a Psiquiatria e a Pedagogia, por exemplo.

Desse modo, desde as práticas presentes na vida monástica, passando pelos processos de coerção jurídica e moral sobre a doença mental e a criminalidade, até o nascimento das ciências humanas, percebe-se os desdobramentos da confissão em 
múltiplas formas de discursividades, de práticas de poder e de processos de subjetivação voltadas para a revelação de uma verdade intrínseca ao sujeito. Desse modo, em termos provocativos, poder-se-ia afirmar que a relação entre pecado e salvação é deslocada para a intensificação de dispositivos biopolíticos voltados para a exegese da subjetividade desde os seus segredos mais íntimos.

Para Leme (2012), tal procedimento destacado por Foucault acaba por ressaltar que o sujeito ocidental, desde o cristianismo, torna-se um animal confidente condicionado a produzir uma experiência ética responsável pela obediência irrestrita e pela desconfiança de si mesmo como categorias de produção de modos de condutas e controles sobre a existência.

O fato de termo-nos constituídos como sujeitos confidentes - graças a diferentes estilos hermenêuticos - pode nos levar a crer que somos capazes de procedermos as nossas verdades interiores, chamadas no mundo contemporâneo de identidades. Entretanto, ao aceitarmos o desafio proposto por Foucault em relação a um distanciamento e uma desconstrução desse processo, em nome do exercício agônico de outras formas de subjetivação, podemos perceber que, na modulação da experiência da veridicção cristã encontra-se os indicativos estruturais dos nossos processos de assujeitamentos.

A obrigação da verdade no cristianismo consiste, nesse caso, no desenvolvimento de uma aleturgia pela qual o sujeito procede o conhecimento de si pelo rastreamento de uma interioridade inatingível, mas ao mesmo tempo desejada. Essa exegese do desejo fundamenta toda uma história da verdade e da subjetividade no contexto das práticas sociais. Essa perspectiva aponta para o fato de que a obrigação de se conhecer a verdade interiorizada torna-se objeto incessante da vontade de saber a partir daquilo que o sujeito é mas, também, daquilo que o sujeito deseja ser. Mas, a pergunta que permanece é: quais vínculos epistemológicos e, ao mesmo tempo, metodológicos, se formam entre esse desejar ser proveniente da governamentalização cristã e outros saberes modernos? Aqui reside um problema muito complexo no pensamento foucaultiano, pois ele envolve a sua aproximação crítica em relação a psicanálise desde suas formulações críticas em $A$ Vontade de Saber (FOUCAULT 1977) e outros cursos promovidos no Collège de France, dedicado a compreensão de uma leitura profana, por assim dizer da tragédia de Édipo. ${ }^{4}$ A respeito dessa análise do sujeito desejante a partir das relações entre verdade e subjetividade, Hernani Chaves reconhece o grau de complexidade da possibilidade aberta por Foucault em relação aos seus últimos trabalhos, pois ele lembra que:

Essa "verbalização" vai ampliar-se e tornar-se cada vez mais complexa, na medida em que o mecanismo da confissão passar a ser utilizado no âmbito da justiça penal, da criminologia, da psiquiatria, da pedagogia, da psicologia e - por que não? - da psicanálise: essa era a tese já expressa em A vontade de saber (1976b, p. 34). Tese problemática à época, porque parecia pouco explicitada e, principalmente, equivocada. É exatamente aqui que se insere minha posição, ou seja, a de sinalizar, levando em consideração as diversas posições que Foucault assumiu em relação à Psicanálise, de que ele pensa justamente na psicanálise quando intenta realizar uma "genealogia do sujeito do desejo". Em outras palavras: em que medida todo esse percurso, que faz um "retorno aos gregos" e depois investiga os primeiros anos do Cristianismo não é inteiramente estranho a um saber surgido no final do século XIX? Como então ligar esses fios, em geral emaranhados, que vão do "sujeito de desejo" ao "sujeito do desejo"? Essa é uma tarefa da qual me ocuparei nos próximos anos (CHAVES, 2019, p. 276).

Essa perspectiva é muito importante para que possamos compreender o grau de complexidade do pensamento foucaultiano em relação aos desdobramentos dos modos 
de veridicção no cristianismo e sua correlação com a produção de subjetividades. Entretanto, pode-se afirmar que as ressonâncias das práticas aletúrgicas desenvolvidas na problematização foucaultiana são um importante indicativo acerca dos tensionamentos existentes entre as práticas de poder, as estratégias de saber e os processos de subjetivação. Desse modo, o estudo sistemático sobre o cristianismo e suas formas de verdades, podem operar como ferramentas para a elaboração de outras práticas de resistência deslocando-as dos efeitos tradicionais de uma revelação de uma interioridade, para a composição performática de outras formas de vida.

\section{REFERÊNCIAS}

AGAMBEN, Giorgio. Altíssima Pobreza: regras monásticas e formas de vida. São Paulo: Boitempo, 2014.

CANDIOTTO, Cesar. Foucault: uma história crítica da verdade. Trans/Form/Ação. 29 (2), 65-78, 2006 . Disponível: <http://www.scielo.br/scielo.php?script=sci_arttext\&pid=S010131732006000200006\&lng=en\&nrm=iso > . Acesso: 30/01/2020.

CANDIOTTO, Cesar. A Prática da Direção de Consciência em Foucault: da vida filosófica à vida monástica cristã. In: CANDIOTTO, Cesar. SOUZA, Pedro. Foucault e o Cristianismo. (pp. 93-110). Belo Horizonte: Autêntica, 2012.

CHAVES, Ernani Pinheiro. Do "Sujeito de Desejo" ao "Sujeito do Desejo": Foucault leitor de Santo Agostinho. Aurora. 31 (52), 257-277, 2019. Disponível: $<$ https://periodicos.pucpr.br/index.php/aurora/article/view/24812/23344>. $\quad$ Acesso: $01 / 02 / 2020$.

CHEVALIER, Philippe. O Cristianismo Como Confissão em Michel Foucault. In: CANDIOTTO, Cesar. SOUZA, Pedro. Foucault e o Cristianismo. (pp. 45-56). Belo Horizonte: Autêntica, 2012.

COLOMBO, Agustin. Hermenéutica de sí y fin de la exomologesis: Michel Foucault y la exclusion de la materialidad de la verdicción en el cristianismo. Aurora. 27 (41), 595614, 2015.

DREYFUS, Hubert. RABINOW, Paul. Michel Foucault: uma trajetória filosófica para além do estruturalismo e da hermenêutica. Rio de Janeiro: Forense Universitária, 1995.

FOUCAULT, Michel. História da Sexualidade I: a vontade de saber. Rio de Janeiro: Graal, 1977.

FOUCAULT, Michel. Segurança, Território, População. São Paulo: Martins Fontes, 2008.

FOUCAULT, Michel. Governo de Si e dos Outros. São Paulo: Martins Fontes, 2009.

FOUCAULT, Michel. Omnes et Singulatim: uma crítica da razão política. In: FOUCAULT, Michel. Ditos e Escritos IV: estratégia, poder-saber. (pp. 348-378). Rio de Janeiro: Forense Universitária, 2010.

FOUCAULT, Michel. A Verdade e as Formas Jurídicas. Rio de Janeiro: NAU, 2011.

FOUCAULT, Michel. A Hermenêutica do Sujeito. São Paulo: Martins Fontes, 2013.

FOUCAULT, Michel. Sexualidade e Poder. In: FOUCAULT, Michel. Ditos e Escritos V: ética, sexualidade, política. (pp. 55-75). Rio de Janeiro: Forense Universitária, 2014a.

FOUCAULT, Michel. Obrar Mal, Decir la Verdad: la funcion de la confesion en la justicia. Buenos Aires: Siglo Veitiuno, 2014b.

FOUCAULT, Michel. Aulas Sobre a Vontade de Saber. São Paulo: Martins Fontes, 2014c.

FOUCAULT, Michel. Do Governo dos Vivos. São Paulo: Martins Fontes, 2016.

FOUCAULT, Michel. Subjetividade e Verdade. São Paulo: Martins Fontes, 2018.

FOUCAULT, Michel. Histoire de La Sexualité IV: les aveux de la chair. Paris: Gallimard, 2019.

JÉRÔME, Lamy. Dire-vrai, aveu et discipline: Michel Foucault et les techniques de vérité. Revue Philosophique de la France et de l'étranger. 143 (2), 201 - 218. Disponível: https://www.cairn.info/revue-philosophique-2018-2-page-201.htm\#. Acesso: 01/02/2019.

LEME, José Luis Câmara. A Desrazão, a Confissão e Profundidade do Homem Europeu. A Prática da Direção de Consciência em Foucault: da vida filosófica à vida monástica cristã. 
In: CANDIOTTO, Cesar. SOUZA, Pedro. Foucault e o Cristianismo. (pp. 45-56). Belo Horizonte: Autêntica, 2012.

MUCHAIL, Salma Tannus. FONSECA, Márcio Alves da. Parresia e confissão: uma genealogia do sujeito moderno. Aurora. 31 (52), 191 - 208, 2019. Disponível: https://periodicos.pucpr.br/index.php/aurora/article/view/24803/23352. Acesso:

$128 \quad 01 / 02 / 2020$.

PORTOCARRERO, Vera. Subjetivação e Veridição no Cristianismo e na Antiguidade Grecoromana. Aurora. 31 (52), $209 \quad$ - 223, 2019. Disponível: https://periodicos.pucpr.br/index.php/aurora/article/view/24811/23361. Acesso: $01 / 02 / 2020$.

\section{NoTAS}

1 A vontade de saber é muito mais do que um subtítulo que ampara à analítica foucaultiana em torno da sexualidade (FOUCAULT, 1977). Na realidade, trata-se de um procedimento metodológico responsável por empreender uma problematização tanto dos regimes de verdades, quanto dos regimes de governamentalidades. Entretanto, Foucault não está interessado em perceber essas duas modalidades como fundamentos ou de uma confiabilidade epistemológica, ou ainda, de um possível estatuto de leitura das sociedades de soberania, mas sim explorar os embates entre as forças pelas quais consolidaram-se ao longo da história, as relações de poder, as estratégias de saber e os processos de subjetivação.

2 No original em francês: Le trouble qu'elle peut introduire prend deux aspects principaux. celui d'abord de la multiplicité, de la mobilité, du désordre, lá où l'ame a besoin d'ordre, de stabilité, d'unité sans mouvement. Aller à la contemplation unique de l'être unique suppose que la pensée se tienne à cette seule fin et jamais n'en dévie.

Tâche extrêmement difficile $<<D e$ qui pourra-t-on creire, fû-il de tous les justes et les saints le plus éminent, qu'il ait réussi, dans les liens de ce corpos mortel, à posséder immuablement le bien souverain, ne s'écartant jamais de la contemplation divine, ne se laissant point distraire un istant, par les pensées terrestres.

3 No original: "El doctor Leuret: En todo eso no hay una sola palabra que sea verdadera; usted dice locuras. Y porque está loco lo retenemos en Bicêtre. El enfermo: No creo que esté loco. Sé lo que vi y oí. El doctor Leuret: Si quiere que esté contento com usted, tiene que obedecer, porque todo lo que le pido es razonable. ¿Me promete no pensar más en sus locuras, me promete no hablar más de ellas? Michel Foucault: Vacilante, el enfermo promete. El doctor Leuret: Muchas veces ha falatado a su palabra sobre este punto: no quiero contar con sus promessas; va a recibir uma ducha hasta que confiese que todas las cosas que dice no son más que locuras. Posteriormente é aplicada a primeira ducha sobre o sujeito que, imediatamente reconhece que suas imaginações não fazem parte da realidade. El enfermo: Sí senor, todo lo que le dije son locuras. El doctor Leuret: ¿Estaba loco, entonces? El enfermo: Creo que no. Michel Foucault: Tercera ducha helada. El doctor Leuret: ¿Estaba loco? El enfermo: ¿Ver y oír es estar loco? El doctor Leuret: Sí. El enfermo: No había mujeres que me insultaban ni hombres que me perseguían. Todo eso es uma locura.

4 Referimo-nos aqui aos cursos Do Governo dos Vivos, Aulas Sobre a Vontade de Saber, Subjetividade e Verdade e Governo de Si e dos Outros. Em todos esses cursos Foucault recorre a diferentes análises genealógicas acerca da tragédia de Édipo certamente para problematizar os aspectos ligados a essencialização, promovida pela psicanálise dessa tragédia. Entretanto, percebe-se nas entrelinhas dessas leituras que, transversalmente Foucault tenta nos apresentar uma espécie de alegoria do sujeito desejante a partir dos pontos de tensionamentos entre verdade e subjetividade. Ver mais detalhes em: Foucault: 2016, 2014c, 2018 e 2009. 